\title{
A deterministic approach to contingency tables
}

\author{
Giorgio Gambirasio (giga@uol.com.br)
}

\begin{abstract}
A tool has been developed to evaluate correlation between variables in $2 \times 2$ contingency tables of categorical data. The work is based on elementary Set Theory and does not make use of probabilistic and random variable concepts. This evaluator distinguishes between a negative and a positive correlation and may be an useful complement to chi-square test.
\end{abstract}

Keywords: contingency tables, set theory, probability, correlation, chisquare test, biological sciences.

\section{Introduction}

This document introduces a simple tool, believed to be new, designed to analyze contingency tables. Contingency tables are mostly used in social sciences, biological and health sciences. They have been studied by statisticians since long ago, resulting in a great amount of available information on the topic.

Of course, all such studies are always made from the point of view of Probability Theory and Statistics, by using assumptions like: experimental results are random variables; such variables obey certain distributions; and similar ones. Main problem is to determine whether effect is independent of supposed cause and, if not, what probability may be assigned to the resulting correlation. This approach (or model) to study contingency tables may be labeled "probabilistic".

In a probabilistic approach, the most popular tool to test a contingency table for correlation is Pearson's chi-square $\left(\chi^{2}\right)$ test, which informs about probability of correlation. This test suffers from at least one serious problem: it does not specify whether a correlation is positive or negative.

A different approach (or model) is described here, which results in a new evaluator of the correlation between cause and effect. The approach does not make use of probabilistic concepts, but relies on concepts of elementary Set Theory only. Therefore, it is labeled "deterministic".

The deterministic evaluator is a signed number, therefore also showing, besides the strength of correlation, whether the correlation is positive or negative. For example, when applied to the case of Titanic disaster, it shows which class is favored for survival and which not. This evaluator does not inform about probabilities.

It is also shown in the paper that it is possible to join the good qualities of both approaches (sign and probability of correlation) into what is called a probabilistic flavor that may be added to a deterministic evaluator. 


\section{Deterministic approach}

Since the approach we are presenting is deterministic (i.e. non-probabilistic), to avoid confusion we will refrain to make use of terms already pertaining to Probability Theory and Statistics and with precise meaning in those fields. Therefore we shall use association or dependence in place of correlation, and to correlate becomes to associate.

Finding a replacement for terms like variables, and especially random variables, is more difficult. Concepts like randomness do not exist in a deterministic world. Perhaps among words like object, thing, fact we could find a suitable replacement for variable. So, we announce that the focus of our discussion is on $2 \times 2$ contingency tables involving categorical things.

As a working tool, we shall make use of elementary Set Theory, with a few modifications regarding notation. We only deal with sets representing subjects in a contingency table.

All sets of concern are disjoint subsets of a total set $\mathrm{T}$, the set that represents the grand total number of subjects in an experiment whose results are mapped on a contingency table.

Complement of a set A is written not-A. Null set is written $\varnothing$.

Content of a generic set $\mathrm{A}$, written \#(A), is the non-negative number that appears in the place occupied by $\mathrm{A}$ in the table. Contents are numbers, not sets. The content of the union of disjoint set is the sum of contents.

Some other properties are:

$\#(\mathrm{~A} \cup$ not- $\mathrm{A})=\#(\mathrm{~A})+\#($ not $-\mathrm{A})=\#(\mathrm{~T})$;

$\#(\varnothing)=0$, therefore $\varnothing$ is the empty set;

not-T $=\varnothing$;

$\#(\mathrm{~A} \cap$ not- $\mathrm{A})=0$;

$\#(\mathrm{~K})=\#(\mathrm{~K} \cap \mathrm{L})+\#(\mathrm{~K} \cap$ not-L $)$;

These properties closely follow similar properties in Probability Theory.

Now, suppose that an experiment is performed to evaluate whether a desired effect $\mathrm{Y}$ is related to a supposed cause $X$ (like, the healing of a disease by a drug) .

The total sample \#(T) of subjects participating in the experiment is divided in $\#(X)$ subjects performing action $\mathrm{X}$ (like taking the drug) and \#(not-X) subjects not performing action $\mathrm{X}$ (like not taking the drug).

Furthermore, the sample is also divided in $\#(Y)$ subjects that show the desired effect and \#(not-Y) subjects showing no effect or not the desired effect. As usual, results are arranged in a $2 \times 2$ contingency table like Table 1 . Cells $C_{i j}(i, j=1,2)$ in Table 1 are shown with a greyed background.

As the few lines above show, content descriptions tend to become long, therefore we will frequently replace them by short-hands, especially in tables. For example, in Table 1 the long expression "Total number of subjects known to perform the action \#(X)" is replaced by a shorter "Total of acting causes \#(X)" 
Table 1 - Typical $2 \times 2$ contingency table

\begin{tabular}{|c|c|c|c|}
\hline Effect $\rightarrow$ & $\begin{array}{c}\text { Desired effect } \\
\text { Y }\end{array}$ & \begin{tabular}{|c} 
Non desired effect \\
not-Y
\end{tabular} & $\begin{array}{l}\text { Marginal } \\
\text { Totals }\end{array}$ \\
\hline $\begin{array}{l}\text { Acting } \\
\text { cause } \\
\quad \mathrm{X}\end{array}$ & $\#(X \cap Y)$ & $\#(X \cap$ not-Y $)$ & $\begin{array}{l}\text { Total of acting } \\
\text { causes } \\
\#(X)\end{array}$ \\
\hline \begin{tabular}{|} 
Inactive \\
cause \\
not-X
\end{tabular} & $\#($ not $-\mathrm{X} \cap \mathrm{Y})$ & $\#($ not- $X \cap$ not-Y $)$ & $\begin{array}{c}\text { Total of inactive } \\
\text { causes } \\
\#(\text { not-X) }\end{array}$ \\
\hline $\begin{array}{c}\text { Marginal } \\
\text { Totals }\end{array}$ & $\begin{array}{c}\text { Total of desired } \\
\text { effect } \\
\#(Y) \\
\end{array}$ & $\begin{array}{c}\text { Total of non desired } \\
\text { effects } \\
\#(\text { not-Y) }\end{array}$ & $\begin{array}{c}\text { Total of sample } \\
\#(\mathbf{T})\end{array}$ \\
\hline
\end{tabular}

In a contingency table, the following equations always hold:

$\#(X \cap Y)+\#(X \cap$ not- $Y)=\#(X)=$ total of acting causes,

$\#($ not- $X \cap Y)+\#($ not $-X \cap$ not- $Y)=\#($ not $-X)=$ total of inactive causes,

$\#(X \cap Y)+\#($ not $-X \cap Y)=\#(Y)=$ total of desired effects;

$\#(X \cap$ not- $Y)+\#($ not $-X \cap$ not- $Y)=\#($ not-Y $)=$ total of non desired effects,

$\#(X)+\#($ not $-X)=\#(Y)+\#($ not $-Y)=\#(T)=$ total number of subjects in sample.

What is wanted from table analysis is answering two questions:

1) Is there an association between cause $X$ and desired effect $Y$ ?

2) If the answer to the first question is yes, how can the association's strength be measured within the frame of our deterministic description?

If the answer to the first question is no, then $\mathrm{X}$ and $\mathrm{Y}$ are independent of each other (an important special case) and the second question has no meaning.

As a starting point, define a quantity $\mathrm{P}(\mathrm{Y} \mid \mathrm{X})=\#(\mathrm{Y} \cap \mathrm{X}) / \#(\mathrm{X})$, called "proportion of set $Y$ content in relation to set $X$ content", with $\#(X) \neq 0$. This quantity (a non-negative number) measures how strongly the desired effect is associated with an active cause.

Similarly, quantity $\mathrm{P}(\mathrm{Y} \mid$ not- $\mathrm{X})=\#(\mathrm{Y} \cap \operatorname{not}-\mathrm{X}) / \#($ not-X), with $\#($ not $-\mathrm{X}) \neq 0$, called "proportion of set $\mathrm{Y}$ content in relation to set not-X content", measures how strongly the desired effect is associated with an inactive cause.

Please notice that letter "P" here does not mean or even suggest "probability"; all expressions are written in an entirely deterministic, non-random world.

Now, suppose that these two proportions computed from a contingency table are found to be equal:

$$
\#(\mathrm{Y} \cap \mathrm{X}) / \#(\mathrm{X})=\#(\mathrm{Y} \cap \operatorname{not}-\mathrm{X}) / \#(\operatorname{not}-\mathrm{X}) \text {. }
$$


What does the equality mean? It means that the effect $Y$ is the same, irrespective of the cause being active or not. In other words, $\mathrm{X}$ and $\mathrm{Y}$ are independent (the drug is not producing the desired effect on the illness at all.)

On the other hand, when the proportions are unequal their difference could be used as a measure of association or dependence. However, it would be useful to have a standardized form to express the association, and for this purpose another quantity is defined, the dependence (or association) evaluator $\operatorname{dep}(\mathrm{Y} \mid \mathrm{X})$ :

$$
\operatorname{dep}(\mathbf{Y} \mid \mathbf{X})=[\mathbf{P}(\mathbf{Y} \mid \mathbf{X})-\mathbf{P}(\mathbf{Y} \mid \text { not-X })] /[\mathbf{P}(\mathbf{Y} \mid \mathbf{X})+\mathbf{P}(\mathbf{Y} \mid \text { not-X })]
$$

This evaluator is a number with values between -1 and +1 . Negative values mean that an increase in $\mathrm{X}$ produces a decrease in $\mathrm{Y}$ (like: more exercise means less cardiovascular diseases). In a probabilistic approach, it would correspond to a "negative correlation between variables". The opposite happens when the evaluator has positive values, when an increase in $\mathrm{X}$ is followed by an increase in $\mathrm{Y}$ (like: more intense smoking leads to more lung cancer). In a probabilistic world it would be referred to as a "positive correlation between variables". Finally, if $\operatorname{dep}(\mathrm{Y} \mid \mathrm{X})=0$, then $\mathrm{Y}$ is independent from $\mathrm{X}$.

Evaluator $\operatorname{dep}(\mathrm{Y} \mid \mathrm{X})$ is proposed here as an alternative tool (or perhaps a complement) to chi-square test in $2 \times 2$ contingency tables.

\section{Worked example of deterministic approach}

Now that a new procedure has been proposed for evaluating association, let us apply it to a specific case as a worked example. Suppose a sample of $\#(T)=1000$ subjects is tested to see how a state or condition $(\#(G)=750$ subjects in good condition, \#(B) $=250$ subjects in bad condition) is associated with a specified activity (\# $(\mathrm{A})=300$ active subjects, $\#(\mathrm{I})=700$ inactive subjects). Possible examples are: physical activity vs. heart condition, or habit of smoking vs. lung cancer. We choose condition as the effect and activity as the cause.

Of course $\mathrm{G}=$ not-B, $\mathrm{I}=$ not $-\mathrm{A}, \#(\mathrm{G})+\#(\mathrm{~B})=\#(\mathrm{~A})+\#(\mathrm{I})=\#(\mathrm{~T})$.

Results are to be presented in a $2 \times 2$ contingency table. However, in order to get a more general view of the case, we make use of the fact that the degree of freedom is 1 , then it is sufficient to specify the content of one cell, and the contents of the other three cells follow. Let the cell ( $\mathrm{B} \cap \mathrm{A}$ ) be specified and let its content be an independent variable $x=\#(\mathrm{~B} \cap \mathrm{A})$. By varying $x$ over its range $x_{\min } \leq x \leq x_{\max }$ one can explore all possible configurations that are compatible with the boundaries that appear on the marginal row and column

Let us call $x^{*}$ the value of $x$ that stays within the possible range. Compatibility with marginal values is assured by checking the following expressions:

a) it must be true that $0 \leq \mathrm{P}(\mathrm{B} \mid \mathrm{A})=\#(\mathrm{~B} \cap \mathrm{A}) / \#(\mathrm{~A}) \leq 1$, then $0 \leq x^{*} \leq \#(\mathrm{~A})$;

b) it must be true that $0 \leq \mathrm{P}(\mathrm{B} \mid \mathrm{I})=\#(\mathrm{~B} \cap \mathrm{I}) / \#(\mathrm{I}) \leq 1$, then $\mathrm{B} \geq x^{*} \geq \#(\mathrm{~B})-\#(\mathrm{I})$.

The interval satisfying both the above inequalities is the allowed range of $x$.

A simpler, practical rule is the following:

a) if $\#(\mathrm{~A})+\#(\mathrm{~B}) \leq \#(\mathrm{~T})$, then $x_{\min }=0$;

b) if $\#(\mathrm{~A})+\#(\mathrm{~B})>\#(\mathrm{~T})$, then $x_{\min }=\#(\mathrm{~A})+\#(\mathrm{~B})-\#(\mathrm{~T})$. 
As for $x_{\max }$, it always equals the lesser value between \#(A) and \#(B):

$x_{\max }=\min [\#(\mathrm{~B}), \#(\mathrm{~A})]$.

First example: $\#(A)=300 ; \#(B)=250 ; \#(T)=1000$, then $x_{\min }=0 ; x_{\max }=250$.

Second example: $\#(A)=800 ; \#(B)=900 ; \#(T)=1000 ;$ then $x_{\min }=700 ; \quad x_{\max }=800$.

Table 2 - Contingency table pertaining to worked example

\begin{tabular}{|c|c|c|c|}
\hline Effect $\rightarrow$ & $\begin{array}{c}\text { Subjects in bad } \\
\text { condition } \\
\text { Bause }\end{array}$ & $\begin{array}{c}\text { Subjects in good } \\
\text { condition } \\
\text { G }\end{array}$ & Totals \\
\hline $\begin{array}{c}\text { Active } \\
\text { subjects } \\
\text { A }\end{array}$ & $\begin{array}{c}\#(\mathrm{~B} \cap \mathrm{A})=x \\
\begin{array}{c}\text { min } \leq x \leq x_{\max } \\
0 \leq x \leq 250\end{array}\end{array}$ & $\begin{array}{c}\#(\mathrm{G} \cap \mathrm{A})= \\
=\#(\mathrm{~A})-x= \\
=300-x\end{array}$ & $\begin{array}{c}\text { Total of active } \\
\text { subjects } \\
\#(\mathrm{~A})=300\end{array}$ \\
\hline $\begin{array}{c}\text { Inactive } \\
\text { subjects } \\
\text { I }\end{array}$ & $\begin{array}{c}\#(\mathrm{~B} \cap \mathrm{I})= \\
=\#(\mathrm{~B})-x= \\
=250-x\end{array}$ & $\begin{array}{c}\#(\mathrm{G} \cap \mathrm{I})= \\
=\#(\mathrm{G})-\#(\mathrm{~A})+x= \\
=450+x\end{array}$ & $\begin{array}{c}\text { Total of inactive } \\
\text { subjects } \\
\#(\mathrm{I})=700\end{array}$ \\
\hline Totals & $\begin{array}{c}\text { Total of subjects } \\
\text { in bad condition } \\
\#(\mathrm{~B})=250\end{array}$ & $\begin{array}{c}\text { Total of subjects in } \\
\text { good condition } \\
\#(\mathrm{G})=750\end{array}$ & $\begin{array}{c}\text { Total of sample } \\
\#(\mathbf{T})=\mathbf{1 0 0 0}\end{array}$ \\
\hline
\end{tabular}

Proportion of bad condition relative to activity is $\mathrm{P}(\mathrm{B} \mid \mathrm{A})=\#(\mathrm{~B} \cap \mathrm{A} / \#(\mathrm{~A})=x / 300$.

Likewise, proportion of bad condition relative to inactivity is given by:

$\mathrm{P}(\mathrm{B} \mid \mathrm{I})=\#(\mathrm{~B} \cap \mathrm{I}) / \#(\mathrm{I})=(250-x) / 700$.

Dependence evaluator follows: $\operatorname{dep}(\mathrm{B} \mid \mathrm{A})=[\mathrm{P}(\mathrm{B} \mid \mathrm{A})-\mathrm{P}(\mathrm{B} \mid \mathrm{I})] /[\mathrm{P}(\mathrm{B} \mid \mathrm{A})+\mathrm{P}(\mathrm{B} \mid \mathrm{I})]$,

$$
\operatorname{dep}(\mathrm{B} \mid \mathrm{A})=(10 x-750) /(4 x+750) \text {. }
$$

Condition for independence is immediately obtained by making $\operatorname{dep}(\mathrm{B} \mid \mathrm{A})=0$; the corresponding value of $x$ will be named $x_{0}$. Then, when independence holds, value $x_{0}=75$ occupies cell \#(B $\left.\cap \mathrm{A}\right)$. To complete the table in case of independence, the remaining cells are computed:

$$
\#(\mathrm{G} \cap \mathrm{A})=225 ; \#(\mathrm{~B} \cap \mathrm{I})=175 ; \#(\mathrm{G} \cap \mathrm{I})=525 .
$$

The value of $x_{0}$ is the same value (\#(B).\#(A)/\#(T)) that a probabilistic approach would give.

Figure 1 graphically shows how dependence evaluator $\operatorname{dep}(\mathrm{B} \mid \mathrm{A})$ changes with $x$. The limits of variation of $x$ are $(0,250)$.

If $\operatorname{dep}(\mathrm{B} \mid \mathrm{A})$ is negative (this happens when $x<x_{0}$ ), the activity would decrease bad conditions (if the contingency table refers to an experiment to detect the influence of physical activity on bad heart condition, the evaluator will likely give a negative value). 
On the other hand, when $\operatorname{dep}(\mathrm{B} \mid \mathrm{A})$ is positive (this happens when $x>x_{0}$ ), the activity would increase bad conditions (if the contingency table refers to an experiment to detect the influence of smoking on lung cancer, the evaluator will likely give a positive value). If $x=x_{0}, \operatorname{dep}(\mathrm{B} \mid \mathrm{A})=0$, and activity and condition are independent.

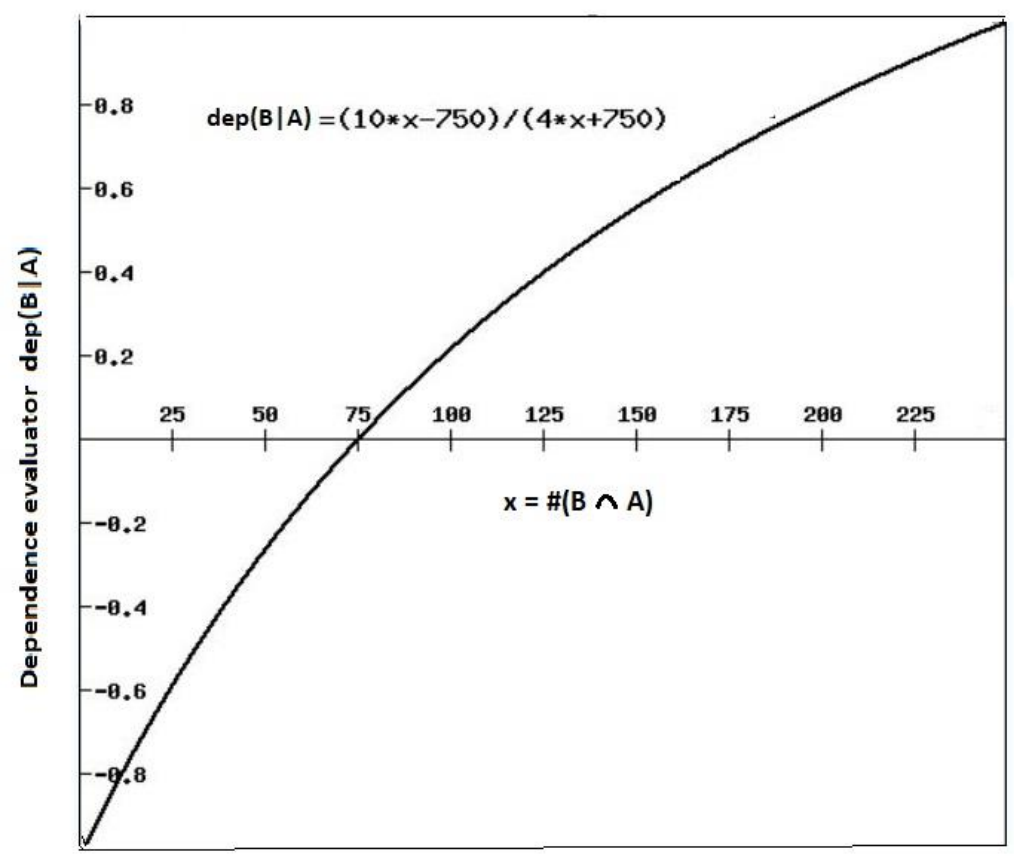

Figure 1 - Plot of dependence evaluator $\operatorname{dep}(\mathrm{B} \mid \mathrm{A})=(10 x-750) /(4 x+750)$. Variable $x=\#(B \cap A)$ is the value that appears on the first cell $\mathrm{C}_{11}$ of table. This evaluator gives a signed information on how strong is the dependence of subject condition on activity. When $\operatorname{dep}(\mathrm{B} \mid \mathrm{A})=0$, condition and activity are independent.

\section{Probabilistic approach}

The probabilistic approach is a topic discussed in Statistics since the $19^{\text {th }}$ century. It is instructive to compare the deterministic evaluator with a popular probabilistic tool, like Pearson's chi-square test $\left(\chi^{2}\right)$. Pearson published his proposal in the year 1900 and since then the test has been much studied and provided with corrections to take care of some of its limitations.

To start, we present a short description of chi-square. Discussion is restricted to $2 \times 2$ contingency table (one degree of freedom).

Let $\mathrm{C}_{\mathrm{ij}}(x)$ represent the numerical value that appears on the cell in row $\mathrm{i}$ and column $\mathrm{j}$, for $\mathrm{i}, \mathrm{j}=1,2$. The idea behind the chi-square test is to observe the difference between the values in $\mathrm{C}_{\mathrm{ij}}(x)$ and $\mathrm{C}_{\mathrm{ij}}\left(x_{0}\right)$ for all values of $\mathrm{i}, \mathrm{j}$. The greater this difference, the greater the value of $\chi^{2}$ and the greater is the probability of association between supposed cause and effect. 
Chi-square is defined by the expression $\chi^{2}=\sum\left[\left(\mathrm{C}_{\mathrm{ij}}(x)-\mathrm{C}_{\mathrm{ij}}\left(\mathrm{x}_{0}\right)\right)^{2} / \mathrm{C}_{\mathrm{ij}}\left(x_{0}\right)\right]$, the sum being taken over $i, j=1,2$. In cases like the one shown on Table $2, x_{0}$ is fixed, and $\chi^{2}$ is a function of $x$ only.

From Table 2 we find that

$$
\mathrm{C}_{11}(x)=x ; \quad \mathrm{C}_{12}(x)=\#(\mathrm{~A})-x ; \quad \mathrm{C}_{21}(x)=\#(\mathrm{~B})-\mathrm{x} ; \quad \mathrm{C}_{22}(x)=x-\#(\mathrm{~A})+\#(\mathrm{G}) .
$$

Let a parameter $k$ be defined by

$$
k=\left(1 / x_{0}\right)+\left[1 /\left(\#(\mathrm{~A})-x_{0}\right)\right]+\left[1 /\left(\#(\mathrm{~B})-x_{0}\right)\right]+\left[1 /\left(x_{0}-\#(\mathrm{~A})+\#(\mathrm{G})\right)\right] .
$$

The final expression for $\chi^{2}$ is:

$$
\chi^{2}=k \cdot\left(x-x_{0}\right)^{2}
$$

This is the equation of a parabola, symmetrical with respect to $x_{0}$.

In statistical jargon, independence is called the zero hypothesis $H_{0}$ and the chi-square test is a test against $H_{0}$ being true. The probability that the effect is independent from the supposed cause is called $p$. As $p$ decreases, the probability that there is a correlation between supposed cause and effect increases.

\section{Adding a probabilistic flavor to the deterministic approach}

It happens that chi-square, when written in the form $\chi^{2}=k \cdot\left(x-x_{0}\right)^{2}$, may be profitably used to establish a bridge between a probabilistic approach and a deterministic approach. According to chi-square theory, $\chi^{2}$ is related to the probability $p$ that the effect be independent of the supposed cause. Such information may be used to add a probabilistic flavor to our deterministic association evaluator. Let us do it:

Note that $k$ does not depend on $x$, only on $x_{0}$ and on properties of the sample, like \#(A) and $\#(\mathrm{~B})$.

First, solve expression of $\chi^{2}$ for $x$, then define values $x_{1}$ and $\mathrm{x}_{2}$, symmetrically placed at each side of $x_{0}$ :

$$
x_{1}=x_{0}-\sqrt{ }\left(\chi^{2} / k\right) ; \quad x_{2}=x_{0}+\sqrt{ }\left(\chi^{2} / k\right) .
$$

When $x<x_{1}$ the probability of independence will be less than the value corresponding to $\chi^{2}$. And when $x>x_{2}$ the probability of independence will also be less than the value corresponding to $\chi^{2}$.

Let us apply these concepts to the case of Table 2 .

The value of $k$ is computed: $k=(1 / 75)+(1 / 225)+(1 / 175)+(1 / 525)=0.0254$. Therefore $\chi^{2}=0.0254 .\left(x-x_{0}\right)^{2}$.

Now, choose a value for probability $p$ :

1) take the most popular value: $p=0.05$, corresponding to $\chi^{2}=3.84$.

Then $\sqrt{ }\left(\chi^{2} / k\right)=12.3 ; \quad x_{1}=62.7 ; \quad x_{2}=87.3$.

This means that when $x<62.7$ or $x>87.3$ the probability $p$ of independence will be less than 0.05 .

In terms of association, it means that when $\operatorname{dep}(\mathrm{B} \mid \mathrm{A})<-0.129$ or $\operatorname{dep}(\mathrm{B} \mid \mathrm{A})>+0.112$, the probability of independence is less than 0.05 . 
2) or, take the second most popular value: $p=0.01$, corresponding to $\chi^{2}=6.64$.

Then $\sqrt{ }\left(\chi^{2} / k\right)=16.2 ; \quad x_{1}=58.8 ; \quad x_{2}=91.2$. Therefore, when $x<58.8$ or $x>91.2$ the probability $p$ of independence will be less than 0.01 .

In terms of association, it means that when $\operatorname{dep}(\mathrm{B} \mid \mathrm{A})<-0.164$ or $\operatorname{dep}(\mathrm{B} \mid \mathrm{A})>+0.145$, the probability of independence is less than 0.01 .

The above values of $x$ and $\operatorname{dep}(\mathrm{B} \mid \mathrm{A})$ appear on Table 3. And Figure 2 shows the result of adding a probabilistic flavor to the case of Table 2. For clarity, the range of $x$ has been restricted to the close neighborhood of $x_{0}$.

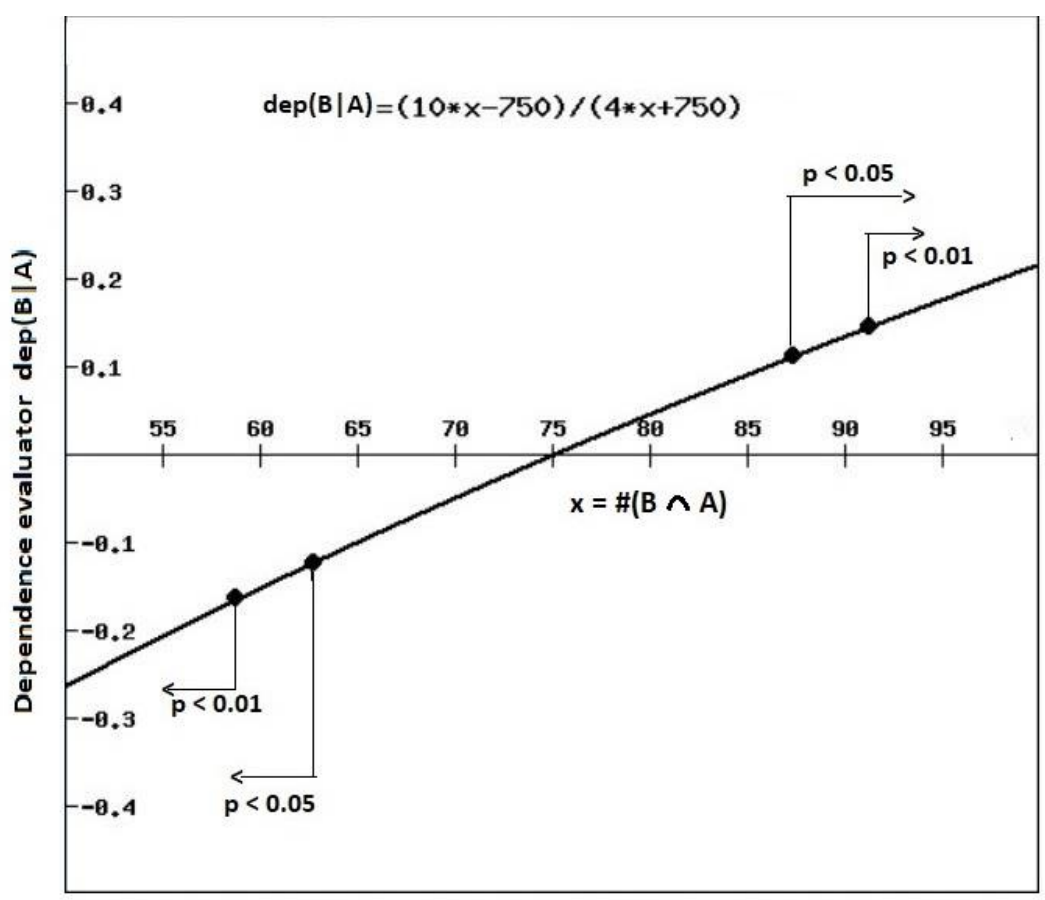

Figure 2 - Plot of $\operatorname{dep}(\mathrm{B} \mid \mathrm{A})$ within a restricted range of $x$ in order to allow for a better view of probabilistic flavor. Dots on curve represent boundaries to variable $x$ relative to probabilities $p=0.05$ and $p=0.01$.

Conclusion: by adding the probability flavor to the deterministic approach one gets information both about probability and about whether the association is positive or negative. Scientists using $\operatorname{dep}(\mathrm{B} \mid \mathrm{A})$ may complete their job with chi-square test. And scientists using chi-square test may decide between positive or negative correlation (see the section on Titanic).

Really, the best of both approaches. 


\section{Comparison of the two approaches}

Table 3 summarizes results obtained when, in Table 2, variable $x$ is given different values within its range. The table compares information given by evaluator $\operatorname{dep}(\mathrm{B} \mid \mathrm{A})$ with information given by chi-square and probability $p$.

It happens that those values of $x$ corresponding to $p=0.05$ and $p=0.01$ are not whole numbers; their subsequent results are written between parentheses in the table.

If one insists that only integers should appear on a table of categorical variables, the rounded numbers are also shown on the table, but without parentheses. Of course there is a small difference between the results.

The cases of $x=0$ (meaning that all subjects in bad condition are inactive) and $x=250$ (meaning that all subjects in bad condition are active) are also shown. In such extreme cases, some cell's values may go to zero and Pearson's probability interpretation is not possible. However, it is certain that the corresponding probability of independence is zero, which means total dependence or association.

Table 3 - Comparison of the two approaches

\begin{tabular}{|c|c|c|c|c|c|c|c|c|}
\hline \multicolumn{7}{|c|}{$\begin{array}{l}\text { Deterministic approach } ; x_{0}=75 ; \#(T)=1000 \\
\#(A)=300 ; \quad \#(I)=700 ; \quad \#(B)=250 ; \quad \#(G)=750\end{array}$} & \multicolumn{2}{|c|}{$\begin{array}{l}\text { Probabilistic } \\
\text { approach } \\
k=0.0254\end{array}$} \\
\hline $\begin{array}{c}\text { Type of } \\
\text { dependence }\end{array}$ & $x$ & $\#(\mathbf{B} \cap \mathbf{A})$ & $\#(\mathbf{G} \cap \mathbf{A})$ & $\#(B \cap I)$ & $\#(\mathbf{G} \cap \mathbf{I})$ & $\operatorname{dep}(\mathbf{B} \mid \mathbf{A})$ & $\chi^{2}$ & $p$ \\
\hline $\begin{array}{l}\text { all subjects in } \\
\text { bad condition } \\
\text { are active } \\
\end{array}$ & 250 & 250 & 50 & 0 & 700 & +1 & 778 & $\mathbf{0}$ \\
\hline $\begin{array}{l}\text { generic, } \\
\text { positive }\end{array}$ & 100 & 100 & 200 & 150 & 550 & +0.22 & $\sim 16$ & $<0.001$ \\
\hline $\begin{array}{l}\text { positive, } \\
p=0.01\end{array}$ & 91.2 & $\begin{array}{c}91 \\
(91.2)\end{array}$ & $\begin{array}{c}209 \\
(208.8)\end{array}$ & $\begin{array}{c}159 \\
(158.8)\end{array}$ & $\begin{array}{c}541 \\
(541.2)\end{array}$ & $+0,145$ & $\begin{array}{c}6.50 \\
(6.64) \\
\end{array}$ & $\begin{array}{c}0.011 \\
(0.010) \\
\end{array}$ \\
\hline $\begin{array}{l}\text { positive, } \\
p=0.05\end{array}$ & 87.3 & $\begin{array}{c}87 \\
(87.3)\end{array}$ & $\begin{array}{c}213 \\
(212.7)\end{array}$ & $\begin{array}{c}163 \\
(162.7)\end{array}$ & $\begin{array}{c}537 \\
(537.3)\end{array}$ & +0.112 & $\begin{array}{c}3.66 \\
(3.84)\end{array}$ & $\begin{array}{c}0.056 \\
(0.050)\end{array}$ \\
\hline $\begin{array}{c}\text { none } \\
\text { (independence) }\end{array}$ & 75 & 75 & 225 & 175 & 525 & $\mathbf{0}$ & 0 & 1 \\
\hline $\begin{array}{l}\text { negative, } \\
p=0.05\end{array}$ & 62.7 & $\begin{array}{c}63 \\
(62.7)\end{array}$ & $\begin{array}{c}237 \\
(237.3)\end{array}$ & $\begin{array}{c}187 \\
(187.3 \\
\end{array}$ & $\begin{array}{c}513 \\
(512.7)\end{array}$ & - 0.129 & $\begin{array}{c}3.66 \\
(3.84)\end{array}$ & $\begin{array}{c}0.056 \\
(0.050)\end{array}$ \\
\hline $\begin{array}{l}\text { negative, } \\
p=0.01\end{array}$ & 58.8 & $\begin{array}{c}59 \\
(58.8)\end{array}$ & $\begin{array}{c}241 \\
(241.2)\end{array}$ & $\begin{array}{c}191 \\
(191.2)\end{array}$ & $\begin{array}{c}509 \\
(508.8)\end{array}$ & - 0.164 & $\begin{array}{c}6.50 \\
(6.64)\end{array}$ & $\begin{array}{c}0.011 \\
(0.010) \\
\end{array}$ \\
\hline $\begin{array}{l}\text { generic, } \\
\text { negative }\end{array}$ & 50 & 50 & 250 & 200 & 500 & -0.26 & $\sim 16$ & $<0.001$ \\
\hline $\begin{array}{l}\text { all subjects in } \\
\text { bad condition } \\
\text { are inactive }\end{array}$ & 0 & 0 & 300 & 250 & 450 & -1 & 143 & $\mathbf{0}$ \\
\hline
\end{tabular}




\section{Titanic}

As last topic in describing $2 \times 2$ contingency tables from a deterministic approach, consider the case of passenger liner Titanic, an example that frequently appears in statistical literature.

On April 1912, passenger boat Titanic hit an iceberg and sank, with loss of many people. Since then Titanic's passenger/crew lists of survived/perished people have been scrutinized and studied to exhaustion by statisticians. Well, let's see what can be said from the deterministic point of view.

Table 4 shows official results from the British Board of Trade Inquiry Report. In the table, people are sorted by passenger class (first, second and third class, whose sets are respectively called $\mathrm{C} 1, \mathrm{C} 2, \mathrm{C} 3$ ). Set $\mathrm{C} 0$ includes everyone not in a passenger class (crew and other on-board personnel). Of a total of 2201 people on board, only 711 survived. Survivors are members of set $\mathrm{S}$ and those who perished are members of the complementary set not-S.

Belonging to a class is chosen to be the supposed cause, surviving or not surviving is the corresponding effect.

Table 4 - Summary of British Board of Trade Inquiry Report on Titanic Disaster

\begin{tabular}{|c|c|c|c|}
\hline Effect $\rightarrow$ & $\begin{array}{c}\text { Survivors } \\
\text { (S) }\end{array}$ & $\begin{array}{c}\text { Perished } \\
\text { (not-S) }\end{array}$ & Marginal Totals \\
\hline First Class (C1) & 203 & 122 & $\#(\mathrm{C} 1)=325$ \\
\hline Second Class (C2) & 118 & 167 & $\#(\mathrm{C} 2)=285$ \\
\hline Third Class (C3) & 178 & 528 & $\#(\mathrm{C} 3)=706$ \\
\hline $\begin{array}{c}\text { Non-passenger } \\
\text { Class (C0) }\end{array}$ & 212 & 673 & $\#(\mathrm{C} 0)=885$ \\
\hline $\begin{array}{c}\text { Marginal Totals } \\
\text { Garand Total }\end{array}$ \\
\hline
\end{tabular}

Table 4 is not a $2 \times 2$ contingency table. However, we shall stay within our modest limits of a $2 \times 2$ table (one degree of freedom) and compute dependence individually for each class, that is, we compute an evaluator dep(survival | class) for each class.

To this effect, when computing the evaluator relative to a given class, all other classes are united together to form the complementary class. Remember that classes are disjoint sets and the content of the union of disjoint sets equals the (numerical) sum of contents.

We shall now show in details how the dependence evaluator of First Class is computed. From Table 4, $\#(C 1)=325 ; \#(S \cap C 1)=203$. Then: $\#($ not-C1 $)=2201-325=1876$; $\#(\mathrm{~S} \cap$ not $-\mathrm{C} 1)=711-303=508 ; \mathrm{P}(\mathrm{S} \mid \mathrm{C} 1)=203 / 325=0.625 ; \mathrm{P}(\mathrm{S} \mid$ not $-\mathrm{C} 1)=508 / 1876$ $=0.271 ; \operatorname{dep}(\mathrm{S} \mid \mathrm{C} 1)=(0.625-0.271) /(0.625+0.271)=0.395$.

Computation of evaluators of remaining classes will follow the example.

Final results are summarized in Table 5. 
Table 5 - Computed survival dependence in Titanic disaster

\begin{tabular}{|c|c|c|c|c|}
\hline Class & First Class & Second Class & Third Class & $\begin{array}{c}\text { Not-passenger } \\
\text { Class }\end{array}$ \\
\hline Dependence & +0.395 & +0.145 & -0.172 & -0.225 \\
\hline
\end{tabular}

Table 5 shows that a person when boarding first class or second class (classes characterized by a plus sign in front of dependence value) had a great chance of surviving, while people in remaining classes (with a minus sign in front of dependence value) were doomed.

Chi-square test would only suggest a strong association between class and survival, without specifying whether survival is favored or hindered by belonging to a specific class. 